\title{
Novel biocatalytic esterification reactions on fatty acids: synthesis of sorbitol 1(6) - monostearate
}

\author{
Ruchi Gulati $^{\text {a }}$ Pragya Aryab, Bhawna Malhotra ${ }^{\mathrm{a}}$, Ashok K. Prasad ${ }^{\mathrm{b}}$, \\ Rajendra K. Saxena ${ }^{\mathrm{a}, *}$, Jayant Kumar ${ }^{\mathrm{c}}$, Arthur C. Watterson, \\ and Virinder S. Parmar ${ }^{b, c, *}$ \\ ${ }^{a}$ Department of Microbiology, University of Delhi South Campus, Benito Juarez Road, \\ New Delhi - 110 021, India; \\ ${ }^{b}$ Bioorganic Laboratory, Department of Chemistry, University of Delhi, \\ Delhi - 110 007, India; \\ ${ }^{c}$ Institute for Nano Science and Engineering Technology, Department of Chemistry, University \\ of Massachusetts, One University Avenue, Lowell, MA 01854, USA \\ E-mail: virparmar@yahoo.co.in \\ Dedicated to Professor Sukh Dev on his $80^{\text {th }}$ birthday \\ (received 16 Jan 03; accepted 06 May 03; published on the web 08 May 03)
}

\begin{abstract}
Aspergillus terreus lipase has exhibited novel capability of catalyzing esterification reaction between fatty acids $\left(\mathrm{C}_{4}-\mathrm{C}_{18}\right)$ and primary, secondary and tertiary monohydric alcohols. Although, the lipase efficiently catalyzed the esterification of saturated stearic acid $\left(\mathrm{C}_{18: 0}\right)$, it failed to accept the monounsaturated oleic acid $\left(\mathrm{C}_{18: 1}\right)$ as the substrate which is also a $\mathrm{C}_{18}$ acid, but has a double bond. Thus, this enzyme has a great potential to be used as a selective catalyst for the separation of almost identical saturated and unsaturated fatty acids in their mixtures. Extending this work, highly efficient and regioselective conversion of sorbitol to its 1(6) - monostearate has been achieved by Aspergillus terreus lipase - mediated esterification in $n$-hexane. Ninety four per cent conversion to the ester was achieved in $12 \mathrm{~h}$ on optimizing four physico-chemical factors, i.e. molar ratios of substrates, temperature, solvent and water activity. Aspergillus terreus lipase immobilized on Accurel was efficient in the synthesis of sorbitol stearate and was reused three times without any significant decline in its activity, yields were further enhanced to $96 \%$ on using the immobilized enzyme.
\end{abstract}

Keywords: Lipase; regioselective; organic medium; esterification; sorbitol 1(6) - monostearate

\section{Introduction}


Fatty acid esters of sugars and sugar alcohols find widespread applications as surfactants/emulsifiers in food, detergents, cosmetics and pharmaceutical industries owing to their biodegradability and low toxicity. ${ }^{1-3}$ Similarly, alcoholic esters of short chain fatty acids are important flavor and aroma compounds, whereas esters of long chain fatty acids are being explored for their use as fuel (biodiesel) ${ }^{3}$ and as waxes ${ }^{3}$ in the oleo-chemical industries. Among these, the fatty acid esters of sorbitol are the second largest class of carboxylic acid esters employed as surfactants. ${ }^{4}$ Their preparation by purely chemical means requires high-energy consumption (acid catalysis and reaction temperatures of $225-250{ }^{\circ} \mathrm{C}$ ) and results in the formation of toxic and colored by-products. Even preferential acylation of primary over secondary hydroxyl groups can rarely be carried out efficiently with free sugars or sugar alcohols. $^{3-5}$ New enzymatic methods involving lipases and proteases are being employed in micro-aqueous/organic media for synthesis of such esters. ${ }^{2,6-9}$

Recently we have reported the use of a lipase from Aspergillus terreus in the synthesis of sorbitan monooleate via trans-esterification on sorbitol. ${ }^{3,10}$ In the present study, the lipase from Aspergillus terreus has been found to catalyze the esterification of fatty acids $\left(\mathrm{C}_{4}-\mathrm{C}_{18}\right)$ with primary, secondary and tertiary alcohols. We also report an efficient and regioselective synthesis of sorbitol 1(6) - monostearate in quantitative yields via direct esterification between sorbitol and stearic acid using $A$. terreus lipase under optimized physico-chemical conditions. The esterification reactions carried out under identical conditions, but in the absence of the enzyme or in the presence of the denatured enzyme instead of the active enzyme do not yield any product.

\section{Results and Discussion}

\section{Esterification of monohydric alcohols}

We had earlier reported that Aspergillus terreus lipase is able to carry out a variety of industrially important esterification reactions for synthesis of sugars, sugar alcohols and ascorbic acid esters with both long and short chain fatty acids in organic medium. ${ }^{11}$ In preliminary investigation, we have observed that the lipase from Aspergillus terreus also catalyses the esterification of fatty acids, e.g. butyric, caproic, caprylic, capric, myristic, palmitic and stearic acids with primary, secondary and tertiary monohydric alcohols. Thus, incubation of an equimolar mixture of a fatty acid and a primary alcohol (methanol / iso-amylalcohol), secondary alcohol (iso-propanol) or tertiary alcohol (tert-butanol) with Aspergillus terreus lipase in $n$ hexane leads to the formation of the corresponding ester in 10-79 \% yields (Scheme 1, Table I). In general, the turn over of the esterification of fatty acids with primary alcohols is more than that of the one with the secondary alcohol, which in turn is more than the turn over in case of the tertiary alcohol. Although the lipase from Aspergillus terreus catalyses the esterification of saturated stearic acid, it failed in the case of esterification of the monounsaturated oleic acid, which is also a monocarboxylic acid with the same number of carbon atoms (Scheme 1); thus this reaction could be useful industrially for efficient separation of such fatty acids which are otherwise quite difficult to separate. Further work to establish this as a more general method by 
studying a large number of saturated and unsaturated fatty acids is under progress in our Laboratories.

$$
\begin{aligned}
& \gamma_{0} \|_{0 H} \\
& \underset{\mathrm{R}-\mathrm{OH}, n \text { - hexane, } 37^{\circ} \mathrm{C}}{\text { Aspergillus terreus lipase }} \\
& \mathrm{n}=2,4,6,8,12,14,16 \\
& \mathrm{CH}_{3}\left(\mathrm{CH}_{2}\right)_{7} \longrightarrow\left(\mathrm{CH}_{2}\right)_{7} \mathrm{COOH} \underset{\text { Aspergillus terreus lipase }}{\mathrm{R}-\mathrm{OH}} \longrightarrow \text { No reaction } \\
& \mathrm{R}=\mathrm{CH}_{3},\left(\mathrm{CH}_{3}\right)_{2} \mathrm{CH},\left(\mathrm{CH}_{3}\right)_{3} \mathrm{C},\left(\mathrm{CH}_{3}\right)_{2} \mathrm{CHCH}_{2} \mathrm{CH}_{2}
\end{aligned}
$$

\section{Scheme 1}

Table 1. A. terreus lipase mediated esterification of fatty acids with primary, secondary and tertiary alcohols in $n$-hexane at $37{ }^{\circ} \mathrm{C}$

\begin{tabular}{lcccc}
\hline Fatty acid & Methanol & iso-Propanol & $\begin{array}{c}\text { \% Conversion after 48 h } \\
\text { iso-Amyl } \\
\text { Alcohol }\end{array}$ & tert-Butanol \\
& & & 70 & \\
Butyric $\left(\mathrm{C}_{4.0}\right)$ & 62 & 33 & 13 & 24 \\
Caproic $\left(\mathrm{C}_{6.0}\right)$ & 41 & 16 & 69 & 10 \\
Caprylic $\left(\mathrm{C}_{8.0}\right)$ & 70 & 14 & 50 & 14 \\
Capric $\left(\mathrm{C}_{10.0}\right)$ & 71 & 32 & 62 & 29 \\
Myristic $\left(\mathrm{C}_{14.0}\right)$ & 79 & 51 & 62 & 35 \\
Palmitic $\left(\mathrm{C}_{16.0}\right)$ & 64 & 50 & 65 & 20 \\
Stearic $\left(\mathrm{C}_{18.0}\right)$ & 66 & 62 & 0 & 0 \\
Oleic $\left(\mathrm{C}_{18.0: 1}\right)$ & 0 & 0 & & 21 \\
\hline
\end{tabular}

Selective esterification of sorbitol. The ability of Aspergillus terreus lipase for catalyzing the esterification reaction between primary, secondary and tertiary alcoholic groups and fatty acids at different rates prompted us to study the regioselective capabilities of the enzyme for the discrimination of primary and secondary hydroxyl groups present in the same molecule. In the present investigation, we have observed that the sorbitol 1(6) - monoester of stearic acid is formed in good yields by $A$. terreus lipase catalyzed esterification of sorbitol involving esterification of one of the two primary hydroxyl groups without any reaction at any of the four 
secondary hydroxyl groups (Scheme 2). In order to achieve maximum conversion of sorbitol into its monostearate, various physico-chemical conditions have been optimized.
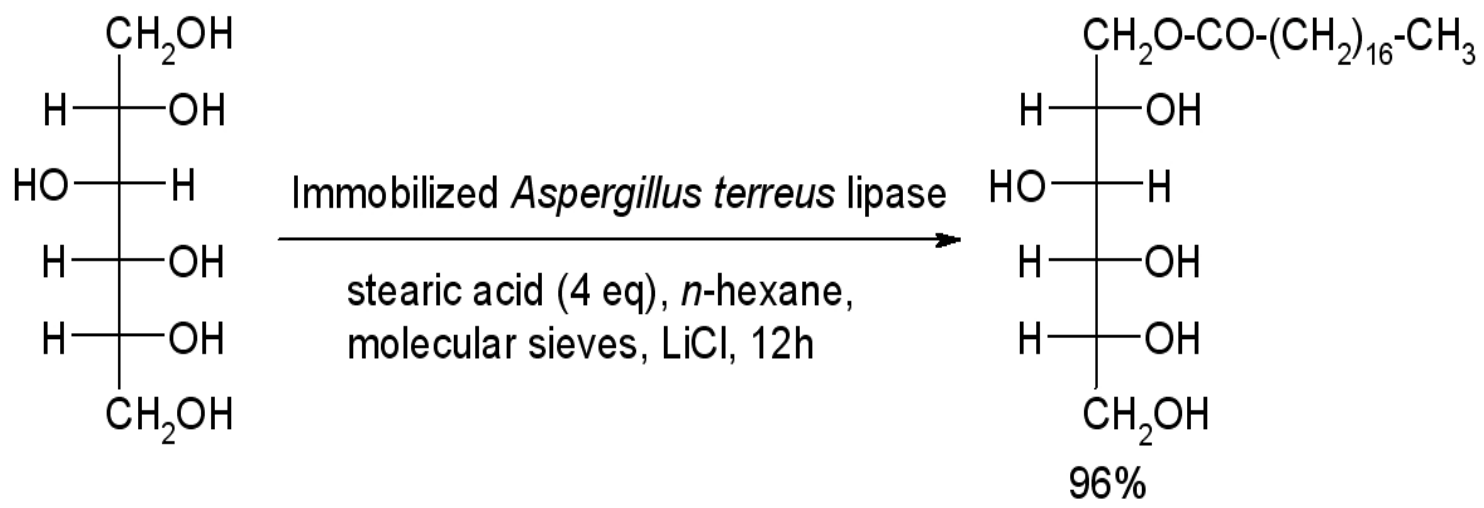

\section{Scheme 2}

\section{Effect of molar ratio of sorbitol and stearic acid}

The sorbitol-stearic acid molar ratio was varied in the range 1:1 to 1:5 in the reaction mixture. It is evident from Table II that a lower sorbitol - stearic acid ratio favored greater yields of sorbitol monostearate. Conversions of nearly $87 \%$ were obtained in $24 \mathrm{~h}$ by mixing sorbitol and stearic acid in the molar ratio of 1:4. No further increase in conversion was obtained on further decreasing the molar ratio. Similar results have been obtained with Candida viscosum lipase catalyzed esterification between sorbitol and oleic acid and with $C$. antarctica lipase mediated synthesis of fructose oleate wherein it was reported that high concentrations of fatty acid in comparison to sugar were necessary for high yields of the ester. ${ }^{5}$

Table 2. Synthesis of sorbitol 1(6) - monostearate at different molar ratios of sorbitol and stearic acid by Aspergillus terreus lipase at $37^{\circ} \mathrm{C}$

\begin{tabular}{lcccc}
\hline $\begin{array}{l}\text { Molar ratio } \\
\text { (sorbitol : stearic acid) }\end{array}$ & $12 \mathrm{~h}$ & $24 \mathrm{~h}$ & $36 \mathrm{~h}$ & $48 \mathrm{~h}$ \\
\hline $1: 1$ & 45.54 & 74.36 & 69.97 & 68.85 \\
$1: 2$ & 69.97 & 81.29 & 81.00 & 80.25 \\
$1: 3$ & 76.25 & 85.45 & 83.21 & 80.24 \\
$1: 4$ & 79.95 & 86.67 & 81.54 & 80.67 \\
$1: 5$ & 78.85 & 86.20 & 84.26 & 79.84 \\
\hline
\end{tabular}


On the other hand, some workers found that an equimolar ratio of substrates favored synthesis of sugar/sugar alcohol esters using lipases from Candida antarctica and Pseudomonas sp., respectively. $^{4,12}$ It is also noteworthy that the percentage of conversion decreased for all the sorbitol to stearic acid molar ratios after $24 \mathrm{~h}$ (Table II). This could have been caused by water absorption by the system due to long reaction times.

\section{Effect of temperature}

The above reaction accelerated upon increase of temperature from $37{ }^{\circ} \mathrm{C}$ to $45{ }^{\circ} \mathrm{C}$ with conversion of about $90 \%$ of sorbitol into its 1(6) - monostearate after which there was a gradual decline (Fig. 1). It is noteworthy to mention that the reaction time for maximum conversion of the acid to its ester was reduced to just $12 \mathrm{~h}$ at $45^{\circ} \mathrm{C}$, further the initial rate of the reaction at 37 ${ }^{\circ} \mathrm{C}$ was low when compared to the rate of the reaction at $45^{\circ} \mathrm{C}, 50^{\circ} \mathrm{C}$ and $60{ }^{\circ} \mathrm{C}$. However after an incubation period of $24 \mathrm{~h}$ at $37^{\circ} \mathrm{C}$, the \% conversion was comparable to that at $45{ }^{\circ} \mathrm{C}$. A significant decline in the conversion of sorbitol to ester was observed after $14 \mathrm{~h}$ of reaction run at $50{ }^{\circ} \mathrm{C}$ and $60{ }^{\circ} \mathrm{C}$ (Fig. 1). This could have been due to the inactivation of the enzyme at higher temperatures in the presence of an organic solvent.

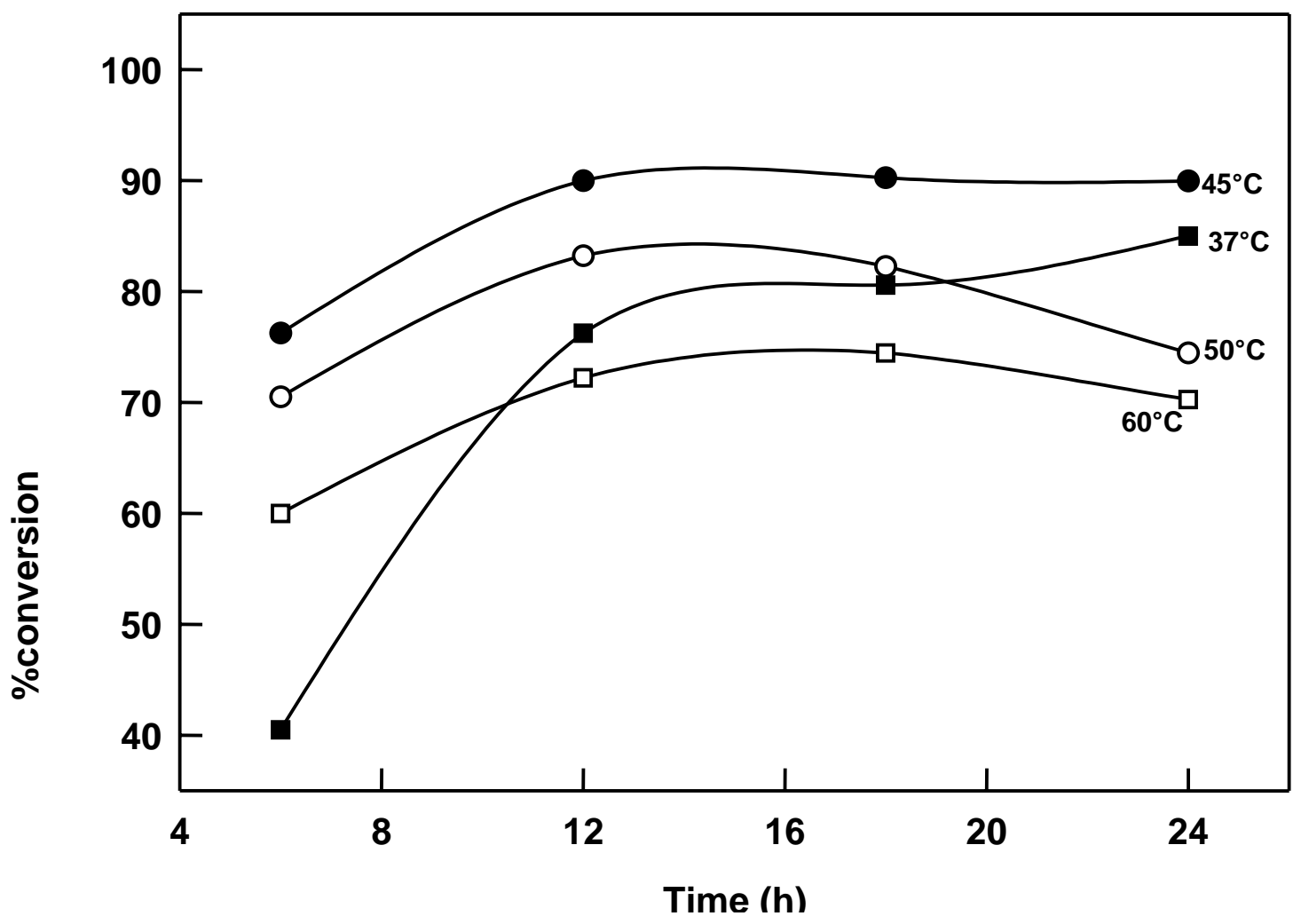

Figure 1. Effect of temperature on the synthesis of sorbitol 1(6) - monostearate in $n$-hexane by Aspergillus terreus lipase at initial $\mathrm{a}_{\mathrm{w}}$ of 0.33 . 


\section{Effect of organic solvents}

Esterification reactions are, generally affected by the type of the solvent. Organic solvents with a higher $\log \mathrm{P}$ value are known to favor greater enzyme stability. ${ }^{8,13,14}$ In the present study, among the different solvents tried (Fig. 2), n-hexane (log $\mathrm{P}$ 3.5) and iso-amyl alcohol ( $\log \mathrm{P} 1.3$ ) affected maximal conversion of $89 \%$ of sorbitol into its 1(6) - monostearate. Pyridine also gave high conversions of $89 \%$ despite of its lower $\log \mathrm{P}$ value (0.71), which may have been due to higher solubility of the substrate sugar alcohol in this solvent. Although the $\log \mathrm{P}$ values of pyridine and $n$-butanol are quite comparable, there are appreciable differences in the \% conversion of sorbitol to ester, this may be because of the differences in solubility of the reactants in these solvents. Lowest yields were obtained in methanol, which has a $\log \mathrm{P}$ value of -0.76 .

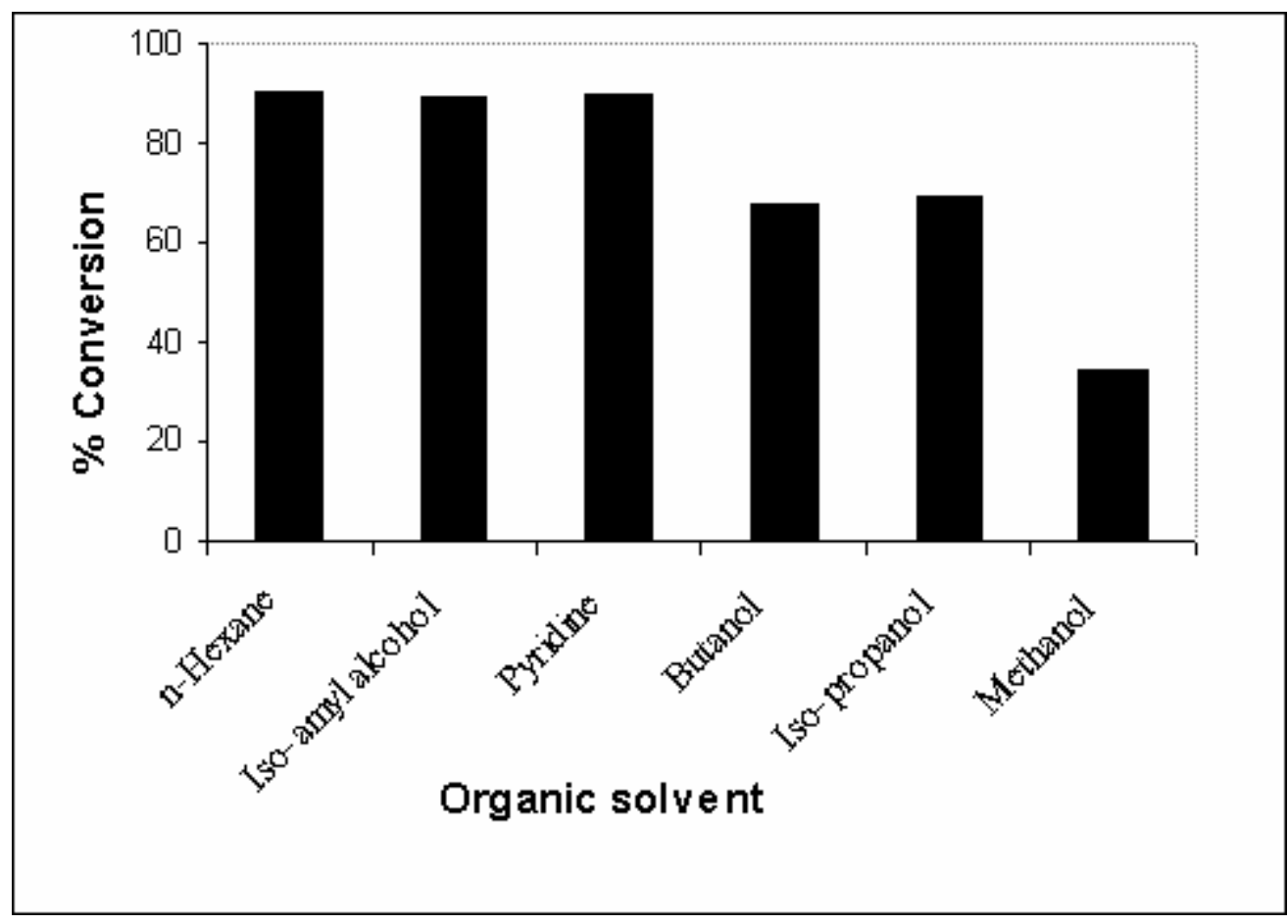

Figure 2. Effect of various organic solvents on the synthesis of sorbitol 1(6) - monostearate at 45 ${ }^{\circ} \mathrm{C}$ and initial $\mathrm{a}_{\mathrm{w}}$ of 0.33 . Log $\mathrm{P}$ values of different solvents used are: $n$-hexane : 3.5; iso-amyl alcohol : 1.3; n-butanol : 0.8; pyridine : 0.71; iso-propanol : 0.28; methanol : -0.76 .

Further, the \% conversion of sorbitol to its monoester seems unaffected by protic and aprotic nature of organic solvents as the turn over of the esterification reaction is almost the same in $n$ hexane, pyridine and isoamyl alcohol (Fig. 2). However, the turn over of the esterification reaction is directly proportional to the lipophilicity of the protic solvents, e.g. the yield of the sorbitol esterification reaction decreases from isoamyl alcohol to butanol and isopropanol, and further to methanol (Fig. 2). A major problem for synthesis of sugar esters is the low solubility of sugar/sugar alcohol in organic solvents. To overcome this problem, generally pyridine or dimethylformamide are used, but these solvents inactivate the enzyme and are non-compatible 
with the industry. ${ }^{6,7,15}$ Other solvents, like chloroform, hexane, acetone, etc. are being used now even though the precursor sugar is not soluble in them. ${ }^{16}$ Investigations on these solvents has, however, revealed that as the reaction proceeds, reactants dissolve because of the higher solubility of the ester formed in such non-polar solvents. Similar results were obtained in the present investigation for synthesis of sorbitol 1(6) - monostearate in $n$-hexane which perhaps is industrially compatible, non-toxic, has a low boiling point and thus can easily be removed from the reaction system. Hexane has also been used for synthesis of 6-O-palmitoyl glucose using Pseudomonas sp. lipase. ${ }^{12}$ Arcos et al. ${ }^{4}$ have used acetone as solvent for the synthesis of 1,6 diacylsorbitol derivatives.

\section{Effect of water activity}

The enzyme-catalyzed reactions in organic media critically depend on the amount of water in the reaction system. ${ }^{17-19}$ The water released during the esterification reaction may disturb the equilibrium and hydrolyze the ester formed. The use of salt hydrates and molecular sieves (type $4 \AA$, at a concentration of $10 \% \mathrm{w} / \mathrm{v}$ of the reaction mixture) is a convenient and simple method to maintain a constant $\mathrm{a}_{\mathrm{w}}$ in the reaction medium. ${ }^{14}$ In the present investigation, the effect of varying initial water activity (using salt hydrates) of the reaction system showed that lower water activity of the reaction system favored higher conversion rates (Table III). It was found that low initial $\mathrm{a}_{\mathrm{w}}$ of 0.11 and 0.33 (obtained with $\mathrm{LiCl}$ and $\mathrm{MgCl}_{2}$, respectively) gave optimal conversion of sorbitol into sorbitol monostearate, i.e. $87.75 \%$ and $85.45 \%$ (Table III). However, higher initial $\mathrm{a}_{\mathrm{w}}$ of 0.97 (using $\mathrm{K}_{2} \mathrm{SO}_{4}$ ) gave conversion of only $70.91 \%$. Kim et al. ${ }^{14}$ used salt hydrate pairs to control $\mathrm{a}_{\mathrm{w}}$ in the reaction mixture for Mucor miehei lipase catalyzed regioselective monoacylation of sucrose. Further, it is interesting to note that even a slight change in the $\mathrm{pH}$ of the reaction causes a considerable change in the \% conversion of sorbitol. Thus $\mathrm{LiCl}, \mathrm{MgCl}_{2}$ and $\mathrm{Mg}\left(\mathrm{NO}_{3}\right)_{2}$ that are the salts of weaker bases and strong acids lower the $\mathrm{pH}$ of the reaction system than the salts $\mathrm{NaCl}$ and $\mathrm{K}_{2} \mathrm{SO}_{4}$ (of strong acid and strong base) show higher conversion rates of sorbitol into its ester (Table III).

Table 3. Effect of initial $\mathrm{a}_{\mathrm{w}}$ of the reaction system on synthesis of sorbitol 1(6) -monostearate after $12 \mathrm{~h}$ at $45^{\circ} \mathrm{C}$ in the presence of different salts

\begin{tabular}{lll}
\hline Salt & $\mathrm{a}_{\mathrm{w}}$ & \% conversion \\
\hline & & \\
$\mathrm{LiCl}$ & 0.11 & 87.75 \\
$\mathrm{MgCl}_{2} \cdot 6 \mathrm{H}_{2} \mathrm{O}$ & 0.33 & 85.45 \\
$\mathrm{Mg}\left(\mathrm{NO}_{3}\right)_{2}$ & 0.53 & 82.45 \\
$\mathrm{NaCl}$ & 0.75 & 71.22 \\
$\mathrm{~K}_{2} \mathrm{SO}_{4}$ & 0.97 & 70.91 \\
\hline
\end{tabular}

The water released during the esterification reaction was controlled by addition of molecular sieves to the reaction system. It was found that the addition of molecular sieves $(10 \% \mathrm{w} / \mathrm{v})$ 
favored higher reaction rates with $96 \%$ conversion in just $12 \mathrm{~h}$ (Fig. 3). This also stabilized the product preventing a backward reaction as observed in the system without the molecular sieves wherein product yields were reduced after $24 \mathrm{~h}$. The addition of molecular sieves had two advantages, firstly it shifted the equilibrium towards ester synthesis. Secondly, it stabilized the product by preventing its hydrolysis by absorbing excess water in the system in comparison to the system without the molecular sieves. Ducret et al. ${ }^{20}$ and Sarney et al. ${ }^{13}$ also used molecular sieves for the removal of water for the esterification of sorbitol with oleic and lauric acids, respectively; higher yields of the esters were obtained which supports our findings.

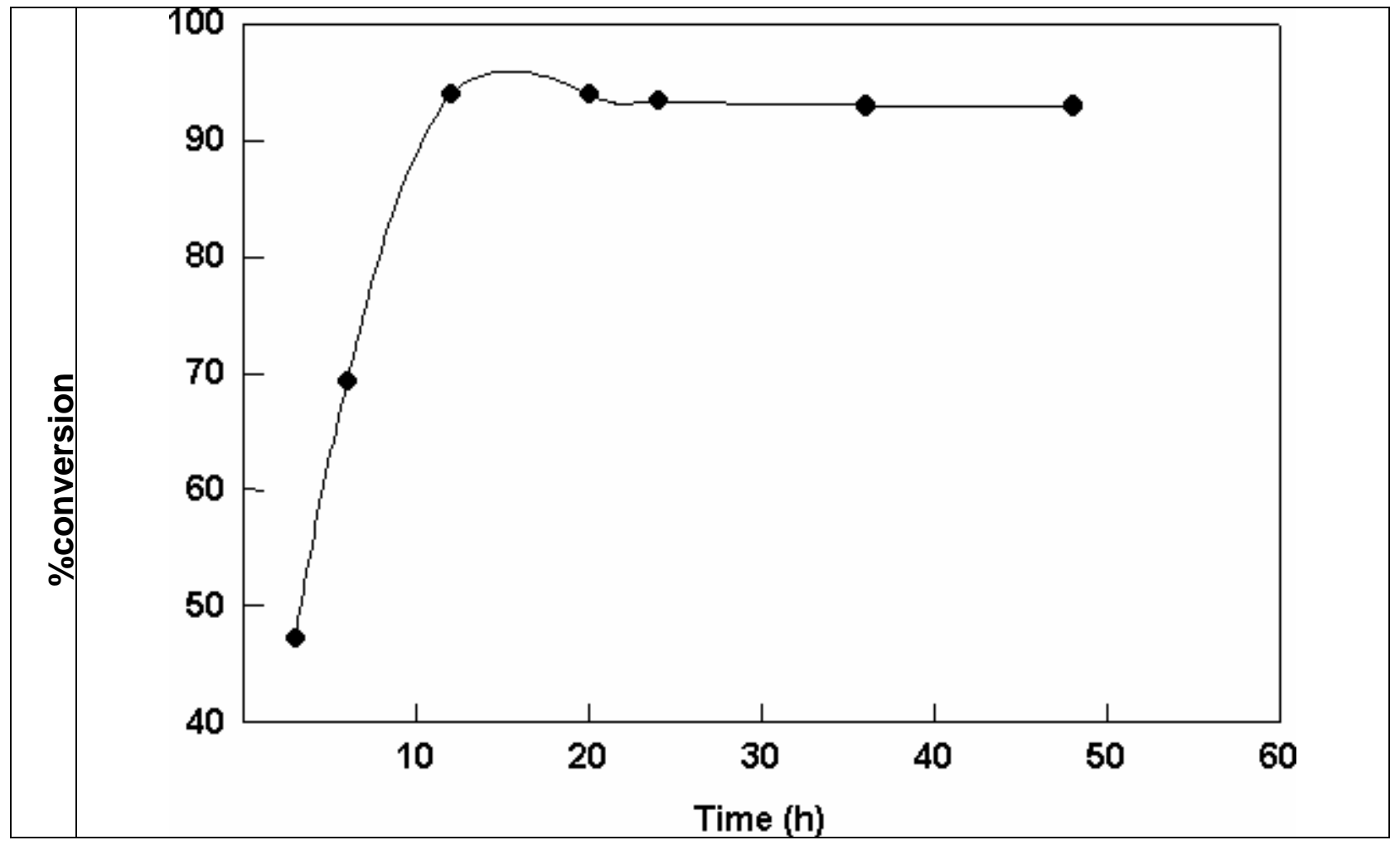

Figure 3. Effect of the addition of molecular sieves (type $4 \AA, 10 \% \mathrm{w} / \mathrm{v}$ ) on the synthesis of sorbitol 1(6) - monostearate by Aspergillus terreus lipase in $n$-hexane at $45^{\circ} \mathrm{C}$.

\section{Synthesis of sorbitol stearate using immobilized $A$. terreus lipase}

The efficiency of the synthesis of sorbitol monostearate was also checked with A. terreus lipase immobilized on Accurel. Enhanced yields of $96 \%$ were obtained on using immobilized lipase. The process could be repeated for three cycles without any significant loss in the selective esterification ability of the enzyme (Fig. 4). 


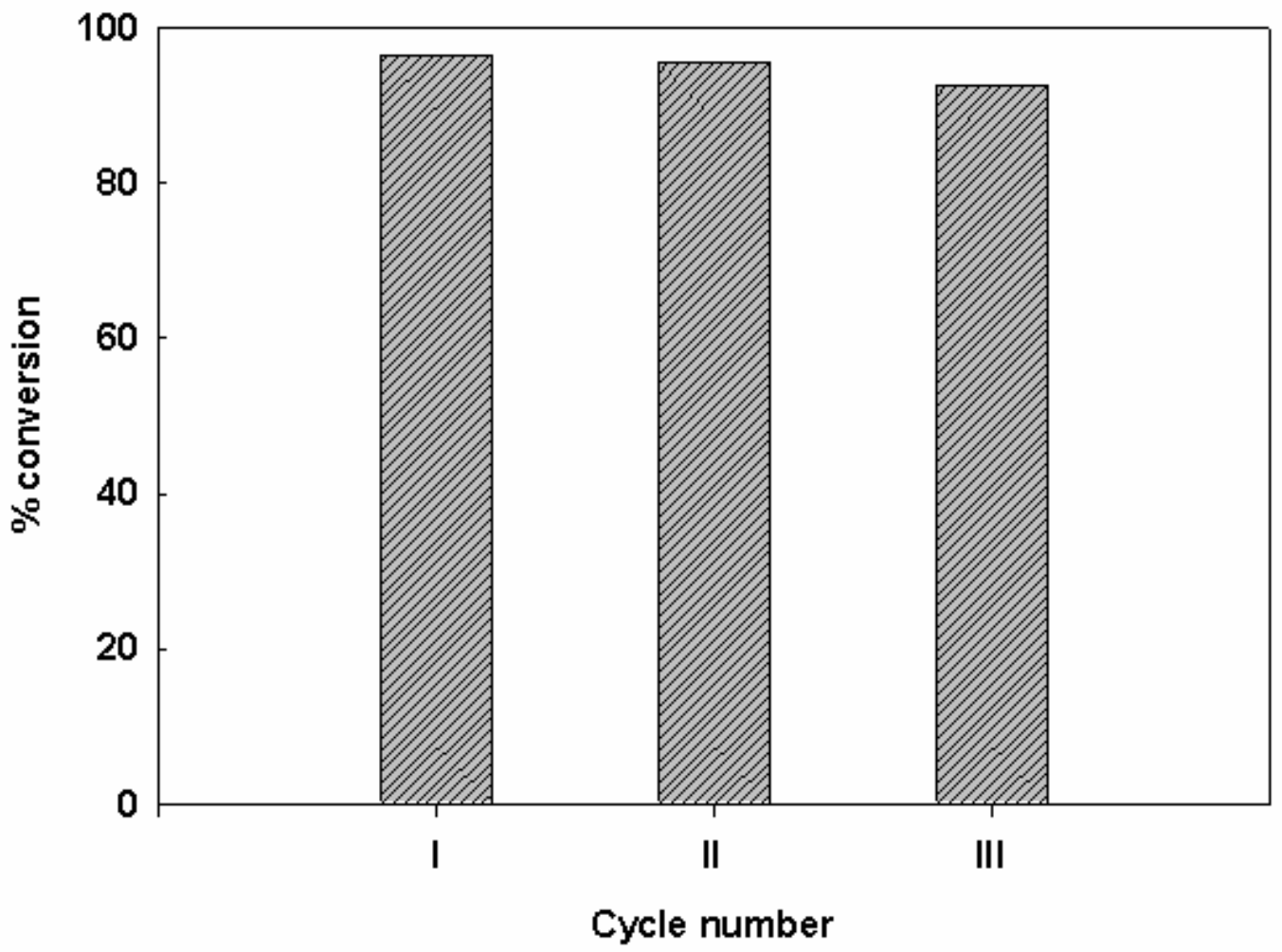

Figure 4. Effect of immobilised Aspergillus terreus lipase on synthesis of sorbitol 1(6) monostearate at $45^{\circ} \mathrm{C}$ and initial $\mathrm{a}_{\mathrm{w}}$ of 0.33 in $n$ - hexane.

\section{Experimental Section}

\section{Microorganism and production medium}

Aspergillus terreus (RKS 101) was grown at $37{ }^{\circ} \mathrm{C}$ and subsequently maintained at $4{ }^{\circ} \mathrm{C}$ on potato dextrose agar slants. Lipase was produced in the medium as previously described using corn oil as the lipidic substrate in a $10 \mathrm{~L}$ fermentor containing $5 \mathrm{~L}$ of the production medium (New Brunswick Sci. Co. Inc., Bio-flow IV fermentor). ${ }^{10,11}$ The medium was autoclaved at 121 ${ }^{\circ} \mathrm{C}$ (15 psi) for $15 \mathrm{~min}$. and inoculated with $1 \times 10^{7}$ spores $/ 50 \mathrm{ml}$ of the medium using $96 \mathrm{~h}$ old culture of A. terreus. Standard operating conditions were: agitation (300 rpm), aeration (1 vvm) and dissolved oxygen concentration not less than $20 \%$ saturation. After $60 \mathrm{~h}$ of the fermentation run, the culture broth containing extracellular lipase was filtered through Whatman No. I filter paper. The culture filtrate containing lipase was partially purified by ammonium sulphate precipitation (60\% saturation). The precipitate containing lipase was dialyzed against $0.01 \mathrm{M}$ 
phosphate buffer (pH 7.0) for 24 h. The dialyzed lipolytic preparation was lyophilized to a dry powder and used in different esterification reactions after storing over $\mathrm{P}_{2} \mathrm{O}_{5}$ in a vacuum dessicator for $24 \mathrm{~h}$.

\section{Aspergillus terreus lipase catalyzed esterification of sorbitol with stearic acid}

Sorbitol (50 mM) and stearic acid (50 mM) were mixed together in $n$-hexane $(4 \mathrm{ml})$ in screwcapped vials $(15 \mathrm{ml})$. The reactants and A. terreus lipases $(50 \mathrm{mg}$, equivalent to $25 \mathrm{U} / \mathrm{mg}$ protein) were equilibrated separately to attain a water activity $\left(\mathrm{a}_{\mathrm{w}}\right)$ of 0.33 with a saturated aqueous solution of $\mathrm{MgCl}_{2} \cdot 6 \mathrm{H}_{2} \mathrm{O}$ for $24 \mathrm{~h}$ in an evacuated dessicator. The reactants and the enzyme were then mixed and incubated at $37{ }^{\circ} \mathrm{C}$ and $150 \mathrm{rpm}$ for $48 \mathrm{~h}$ in a shaker incubator. Periodically, sample aliquots were withdrawn and product formation was qualitatively assessed by TLC analysis. Ester synthesis was expressed as the percentage molar conversion of the acid to the ester after titrating the residual fatty acid against $0.01 \mathrm{M} \mathrm{NaOH}$. The maximum conversion of fatty acid to ester achieved under the conditions was $68.85 \%$ (Table II).

Different physico-chemical factors were studied in order to achieve maximum formation of sorbitol monostearate. These were: molar ratio of substrates, temperature, organic solvent and water activity $\left(\mathrm{a}_{\mathrm{w}}\right)$ control. To study the effect of water activity on the esterification reaction, molecular sieves (type $4 \AA$ ) were added at a concentration of $10 \% \mathrm{w} / \mathrm{v}$ of the reaction mixture. Any deviations from the standard reaction conditions are mentioned at appropriate places.

\section{Lipase immobilization}

For immobilization, Accurel EP 100 beads (200 mg, Enka AG, Obernberg, Germany) were wetted with ethanol ( $2 \mathrm{ml})$. To this, distilled water $(4 \mathrm{ml})$ and sodium phosphate buffer $(0.01 \mathrm{M}$, $2.5 \mathrm{ml}$ ) were added. Lipase powder (200 mg, $20 \mathrm{U} / \mathrm{mg}$ ) in distilled water $(13.5 \mathrm{ml}$ ) was added to the beads and the suspension was shaken at $100 \mathrm{rpm}$ for $12 \mathrm{~h}$ at room temperature for immobilization to occur. The beads were filtered off and washed twice with phosphate buffer to remove any unbound protein and subsequently dried at room temperature under vacuum. The immobilized lipase (50 mg) was added to the optimized reaction mixture of sorbitol and stearic acid. Esterification was carried out at $45^{\circ} \mathrm{C}, 150 \mathrm{rpm}$ and for $12 \mathrm{~h}$. All other reaction conditions were the same as standardized earlier. The immobilized enzyme was used for three cycles to check the efficiency of the enzyme in terms of reusability.

The esterification reactions carried out under identical conditions, but in the absence of the enzyme or in the presence of the denatured enzyme instead of the active enzyme did not yield any product.

\section{Spectral analysis of the reaction products}

After the desired reaction time, the enzyme was removed by filtration. The filtrate was concentrated by evaporation of the solvent in vacuo and the products subsequently purified by column chromatography over silica gel. TLC analysis of the products were carried out on E. Merck pre-coated silica gel plates using the solvent system: petroleum ether - ethyl acetate (19:1). The purified products were analyzed by IR and ${ }^{1} \mathrm{H}$ NMR spectroscopy; the IR spectra 
were recorded on a Perkin -Elmer RX/FT- IR spectrophotometer and the ${ }^{1} \mathrm{H}$ NMR spectra were recorded on a Bruker Avance $300 \mathrm{MHz}$ instrument in $\mathrm{CDCl}_{3}$, the spectra of different esters obtained in this study were fully compatible with their structures and matched well with those reported in the literature for the corresponding compounds.

\section{Conclusions}

A. terreus lipase discriminates between saturated and unsaturated fatty acids towards their esterification reactions with alcohols. Further, very high conversions (96\%) of sorbitol into its 1(6) - monostearate were obtained in only $12 \mathrm{~h}$ by immobilized A. terreus lipase-catalyzed esterification of sorbitol with stearic acid in $n$-hexane on optimizing various physico-chemical conditions. Temperature, water activity control and organic solvent type were the major controlling factors in the conversion of sorbitol to its 1(6) - monostearate. The efficiency of the immobilized lipase, which could be used repeatedly, established the cost-effectiveness of the whole process. Thus, the biocatalytic route described here is economical, efficient and environmentally benign for carrying out esterification reactions of commercial significance.

\section{Acknowledgements}

We thank the Department of Biotechnology (DBT, Government of India, New Delhi) for financial support and Mamta Samtani for technical support in the preparation of this manuscript.

\section{References}

1. Yadav, R. P.; Saxena, R. K.; Gupta, R.; Davidson, W. S. J. Sci. Ind. Res. 1997, 56, 479.

2. Piccicuto, S.; Blecker, C.; Brohee, J.-C.; Mbampara, A.; Lognay, G.; Deroanne, C.; Paquot, M.; Marlier, M. Biotechnol. Agron. Soc. Environ. 2001, 5, 209.

3. Saxena, R. K.; Ghosh, P. K.; Gupta, R.; Davidson, W. S.; Bradoo, S.; Gulati, R. Curr. Sci. 1999, 77, 101.

4. Arcos, J. A.; Bernabe, M.; Otero, C. Biotechnol. Bioeng. 1998, 60, 53.

5. Coulon, D.; Ismail, A.; Girardin, M.; Rovel, B.; Ghoul, M. Biotechnol. 1996, 51, 115.

6. Janssen, A. E. M.; Kalbbers, A.; Franssen, M. C. R.; van't Riet, K. Enzyme Microb. Technol. 1991, 13, 565.

7. Chopineau, J.; McCafferty, F. D.; Therisod, M.; Klibanov, A. M. Biotechnol. Bioengg. 1988, 31, 208.

8. Parmar, V. S.; Kumar, A.; Poonam; Pati, H. N.; Saxena, R. K.; Davidson, W. S.; Gupta, R. Biochim. Biophys. Acta 1998, 1387, 325. 
9. Parmar, V. S.; Pati, H. N.; Yadav, R. P.; Kumar, A.; Bisht, K. S.; Gupta, R.; Davidson, W. S.; Poonam; Saxena, R. K. Biocat. Biotrans. 1998, 16, 17.

10. Yadav, R. P.; Saxena, R. K.; Gupta, R.; Davidson, W. S. Biotechnol. Appl. Biochem. 1998, 28, 243.

11. Gulati, R.; Saxena, R.; Gupta, R.; Yadav, R.P.; Davidson, W.S. Process Biochem. 1999, 35, 459.

12. Tsuzuki, W.; Kitamura, Y.; Suzuki, T.; Kobayashi, S. Biotechnol. Bioengg. 1999, 64, 267.

13. Sarney, D. B.; Barnard, M. J.; Virto, M.; Vulfson, E. N. Biotechnol. Bioengg. 1997, 54, 351.

14. Kim, J. E.; Han, J. J.; Yoon, J. H.; Rhee, J. S. Biotechnol. Bioengg. 1998, 57, 121.

15. Sin, Y. M.; Cho, K. W.; Lee, T. H. Biotechnol. Lett. 1998, 20, 91.

16. Gupta, M. N. J. Biochem. 1992, 203, 25.

17. Halling, P. J. Biotechnol. Bioengg. 1990, 35, 691.

18. Colombie, S.; Tweddell, R. J.; Condoret, J. S.; Marty, A. Biotechnol. Bioengg. 1998, 60, 362.

19. Zaks, A.; Klibanov, A. M. J. Biol. Chem. 1988, 263, 3194.

20. Ducret, A.; Giroux, A.; Trani, M.; Lortie, R. Biotechnol. Bioengg. 1995, 48, 214. 